\title{
Validation of Multiple Solute Model for Application to Micellar Enhanced Ultrafiltration and Comparison with Modified Resistance in Series Model
}

\author{
S.K. Pawar and K.V. Marathe*
}

Department of Chemical Engineering, Institute of Chemical Technology, Mumbai-400019, India

\begin{abstract}
Modified resistance in series model and multiple solute models have been studied for its application in micellar enhanced ultrafiltration (MEUF). Experimental results for separation of $\mathrm{Ni}(\mathrm{II})$ ions from synthetic wastewater with anionic surfactant sodium dodecyl sulfate (SDS) and nonionic surfactant Tween 80 are used for validation of mathematical models. Modified resistance in series model is characterized by model parameters such as specific resistance $\alpha_{0}$, membrane resistance $R_{m}$ and mass transfer coefficient $k$. Whereas, multiple solute model is characterized by the parameters such as membrane resistance $R_{m}$, permeability coefficient $P_{m}$, back transport coefficient $K_{b i}$ and mass transfer coefficient $\mathrm{k}_{\mathrm{i}}$ for each solute in the system. These parameters are estimated by using the Levenberg-Marquardt method coupled with the Gauss-Newton algorithm using MATLAB. The simulation results for multiple solute model are in good agreement with the experimental results as compared to the simulation results obtained by using modified resistance in series model.
\end{abstract}

Keywords: Modeling, Micellar enhanced ultrafiltration, multiple solute model, resistance in series, cross flow, gel polarization.

\section{INTRODUCTION}

Ultrafiltration (UF) process uses a porous membrane to separate water and microsolutes from the solution containing macromolecules and colloids. It is primarily size exclusion based pressure driven separation process. The average pore diameter of the ultrafiltration membrane lies from 10 to $1000 A^{0}$ [1]. Trans-membrane pressure (TMP) plays an important role in calculation of flux. Also, osmotic pressure difference across membrane is an important factor while calculating flux. The key factor determining the performance of the ultrafiltration membranes is the gel polarization where the rejected solutes deposit on the membrane surface. The gel polarization causes membrane fouling and leads to the drop in permeate flux. This gel layer acts as a second barrier [2].

It has been observed that separation of heavy metals like nickel from wastewater can be achieved by using micellar enhanced ultrafiltration [3]. Presently modeling and simulation is very widely used for predicting results in various ultrafiltration systems. A process model is a set of equations that can be used to predict the behavior of a system. Modeling can be valuable because it is an abstraction and helps to avoid repetitive experimentation and observations. A mathematical model is can be developed to provide a conceptual framework for understanding the

*Address correspondence to this author at the Department of Chemical Engineering, Institute of Chemical Technology, Mumbai-400019, India; Tel: 919322276001; Fax: 91-22-24145614; E-mail: kv.marathe@ictmumbai.edu.in phenomenon responsible for flux decline and for calculation of flux, rejection ratio and various parameters in the ultrafiltration process.

A number of mathematical models are available for predicting the permeate flux in classical ultrafiltration processes. Ultrafiltration modeling can be classified in three types. 1. Classical and Empirical models; 2. Mathematical and CFD models and 3. Models based on Artificial Intelligence. Classical models include very simple models such as Osmotic pressure model, gel polarization model, modified osmotic pressure model and boundary layer resistance model. Mathematical and CFD models include various two and three dimensional models. Models based on artificial intelligence (Al) include genetic and neural network $\mathrm{Al}$ models [4]. The most common model used in describing the performance of ultrafiltration is the resistance in series model [5-8]. The main assumption in resistance in series model is that the flux of permeate is proportional to transmembrane pressure and inversely proportional to the viscosity of the suspending solution where the parameter of hydraulic resistance is the total resistance exerted by membrane and solutes [9].

Paris et al. have studied transport phenomenon in ultrafiltration. This study includes comparison between classical models such as osmotic pressure model, gel polarization model with resistance in series model. The resistance in series model used in this study can predict permeate flux for a single solute system [10]. The models proposed in the literature are suitable for 
predicting only permeate flux of UF with single solute systems [11-13]. The hydraulic resistance is the total resistance exerted by the membrane and solutes. Damak et.al developed a fluid dynamic model for cross-flow filtration tubular membranes. A method of coupling the Navier-Stokes and Darcy equations, using a finite difference technique to simulate laminar fluid flow [14]. The permeate flux for multiple solute system can be determined effectively by combining various classical models with each other. The permeate flux in cross flow ultrafiltration for multiple solute system can be determined by using the model, based on the mass balance analysis coupled with the filtration theory (Darcy's law), resistance-in-series and gel polarization models, applicable to multiple solute systems [15].

Separation of nickel (II) from wastewater can be achieved by using MEUF using mixed surfactants, anionic surfactant SDS and nonionic surfactant Tween 80. The behavior of this multiple solute system can be studied using modeling and simulation.

Thus the major objectives of the present study are:

1. To study different mathematical models available for predicting behavior of ultrafiltration systems and to select an appropriate model for multiple solute system.

2. To estimate various model parameters using experimental data for separation of $\mathrm{Ni}(\mathrm{II})$ by micellar enhanced ultrafiltration with mixed surfactants.

3. To validate the mathematical models by comparing simulation results of different models with the experimental data.

\section{EXPERIMENTAL DETAILS}

\subsection{Membrane}

The membrane used in all experiments was polyethersulphone (PES) flat sheet type membrane having $10 \mathrm{kDa}$ molecular weight cut-off (MWCO) and $0.002153 \mathrm{~m}^{2}$ effective membrane area. PES membrane is hydrophobic in nature; it can withstand a wide $\mathrm{pH}$ range of $1-14$. It is compatible with almost all chemicals and can withstand temperature up to $75^{\circ} \mathrm{C}$.

\subsection{Chemicals}

Synthetic wastewater was prepared by dissolving nickel(II) sulphate heptahydrate $\left(\mathrm{NiSO}_{4} .7 \mathrm{H}_{2} \mathrm{O}\right)$ in deionized (DI) water. Nickel (II) sulphate heptahydtrate was procured from Merck Ltd., Mumbai, India. Also the anionic surfactant sodium dodecyl sulphate (SDS) and nonionic surfactant Tween 80 were received from Merck Ltd., Mumbai, India and used without further purification. DI water was used in all experiments. 4-(2Pyridylazo) resorcinol monosodium salt indicator (PAR) was used for analysis of metal ions and Tween 80 surfactant. For analysis of SDS, sodium phosphate $\left(\mathrm{NaH}_{2} \mathrm{PO}_{4} \cdot \mathrm{H}_{2} \mathrm{O}\right)$, chloroform $\left(\mathrm{CCl}_{4}\right)$, sulfuric acid $\left(\mathrm{H}_{2} \mathrm{SO}_{4}\right)$ and methylene blue were procured from S.D. fine chemicals Ltd., Mumbai, India. All chemicals used were of analytical grade.

\subsection{Ultrafiltration Set-Up and Experimental Procedure}

The micellar enhanced ultrafiltration experiments were carried out in a cross flow mode system, from Sartorius, Germany. Synthetic wastewater was prepared by dissolving nickel (II) sulphate heptahydrate in DI water and mixed surfactants SDS and TW80 were added according to surfactant to metal (S/M) ratio. The total $S / M$ ratio of 6 and nonionic to ionic surfactant ratio of 0.2 was used for all the experiments.

The solution was kept in $500 \mathrm{ml}$ feed tank and it was continuously fed to the ultrafiltration cell using peristaltic pump. Permeate and retentate streams were continuously recycled to the feed tank, to ensure that bulk concentration of feed remains constant throughout for the experiment. The schematic representation for UF set up is as in Figure 1. Transmembrane pressure (TMP) was recorded from pressure gauge. $2 \mathrm{ml}$ sample was collected for every run from permeate stream for analysis purpose.

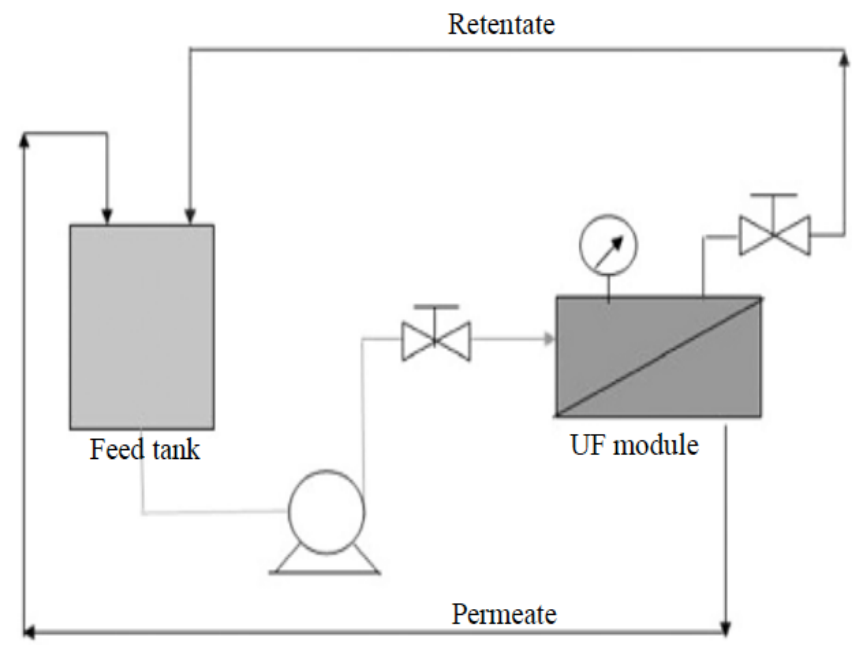

Figure 1: Schematic representation of continuous cross-flow ultrafiltration. 


\subsection{Analysis}

Permeate stream concentration $\mathrm{C}_{\mathrm{P}}$ of $\mathrm{Ni}$ (II) and Tween 80 in permeate sample was determined by UV visible spectroscopy analysis using PAR as reference solution. Analysis of SDS was also carried out using UV visible spectroscopy by MBAS (methylene blue active substances) method for anionic surfactant. Thus the percentage rejection can be determined as

$\%$ Re jection $=\left[1-\frac{\mathrm{C}_{\mathrm{Pi}}}{\mathrm{C}_{\mathrm{Fi}}}\right] * 100$

Where $\mathrm{C}_{\mathrm{Pi}}$ and $\mathrm{C}_{\mathrm{Fi}}$ represents concentration of any solute i, in permeate stream and feed respectively.

\section{DETAILS OF MODELS}

\subsection{Selection of Model}

Selection of an appropriate model depends on various factors such as number of solutes in system, concentration of each solute in feed, operation regime i.e. pressure controlled or mass transfer controlled, mode of operation i.e dead end or cross-flow [3]. In present study for separation of $\mathrm{Ni}$ (II) using mixed surfactants SDS and Tween 80,thus total solutes in system are three. All the solutes are in dilute range and experiment is carried out at different TMP, this suggests that the system is mass transfer controlled. All the MEUF experiments were carried out in crossflow mode and the system is steady state.

Considering all the above factors, the multiple solute model based on the mass balance analysis coupled with the filtration theory (Darcy's law), resistance in series and gel polarization model [15] was selected.

Further the simulation results obtained by using above model are compared with modified resistance in series model. Classical resistance in series model was modified in order to include the influence of mean solute concentration $\bar{C}$ and TMP in to the resistance due to concentration polarization $R_{P}[10]$.

\subsection{The Modified Resistance in Series Model}

The classical resistance in series model does not give physical explanation to limiting flux, in contrary to the other classical models such as gel polarization model and osmotic pressure model. It just relates permeate flux to TMP and several constant resistances due to membrane fouling and gel polarization.
Therefore this classical resistance in series model is modified in order to include the influence of mean solute concentration $\bar{C}$ and transmembrane pressure $(\Delta \mathrm{P})$ in to the resistance due to concentration polarization [10].

Mass balance for the solute retained over the concentration boundary layer as shown in Figure 2. can be written as

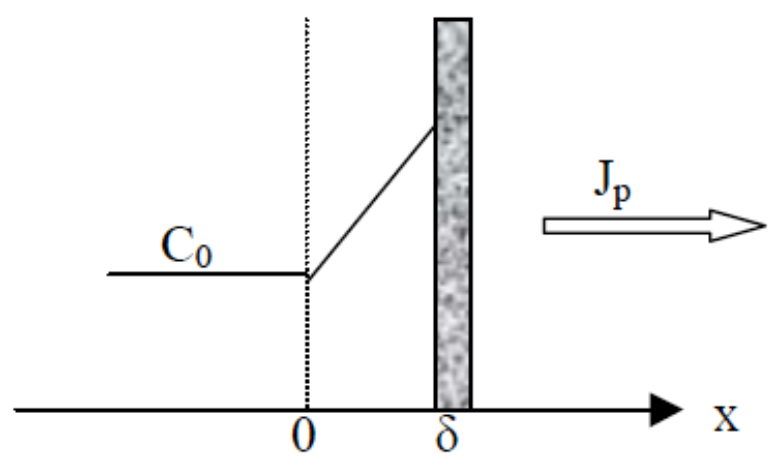

Figure 2: Mass balance over linear concentration profile in boundary layer thickness $\delta$.

$C J_{p}-D \frac{\partial C}{\partial}$

Eq. (2) results in

$C(x)=C_{0} \exp \left(\frac{J_{p}}{D}\right) x$

Where, $\mathrm{C}_{0}$ represents bulk concentration of solute, $D$ is diffusion coefficient and $J_{p}$ is volume flux of permeate. The mean concentration $(\bar{C})$ in the concentration boundary layer of thickness $\delta$ can be written in the form of integration as

$\bar{C}=\frac{\int_{0}^{\delta} C(x) d x}{\delta}$

Therefore substituting value of $C(x)$ from Eq. (3) in to Eq. (4), we get mean concentration as

$\bar{C}=\frac{C_{0}}{P e}(\exp P e-1)$

Where Pe represents Peclet number and is given as

$P e=\frac{J_{p} \delta}{D}=\frac{J_{p}}{k}$

Where, $\mathrm{k}$ is the mass transfer coefficient. The classical resistance in series model is represented as 
$J_{p}=\frac{1}{\mu\left(R_{m}+R_{p}\right)} \Delta P$

Where, $\Delta P$ is transmembrane pressure, $R_{m}$ is the membrane resistance and $R_{p}$ is the resistance due to concentration polarization. $R_{p}$ can be given as $R_{p}=\alpha \delta \bar{C}$. Where, $\alpha$ represents specific resistance of deposited layer on membrane and is given as $\alpha=\alpha_{0} \Delta P$ and $\alpha_{0}$ is called as specific resistance coefficient. Therefore resistance due to concentration polarization is can be given by following equation

$R_{p}=\alpha_{0} \delta \bar{C} \Delta P$

Substituting Eq. (5) in Eq. (8) we get,

$R_{p}=\frac{\alpha_{0} C_{0} \delta}{P e}(\exp P e-1) \Delta P$

Therefore the modified resistance in series model, to determine permeate flux can be represented as below

$$
J_{p}=\frac{\Delta P}{\mu R_{m}+\left(\frac{\alpha_{0} C_{0} \delta \mu}{P e}\right)(\exp P e-1) \Delta P}
$$

Above Eq. (10) can be written in linear form which can be further used to determine model parameters. Thus expression for $\Delta \mathrm{P} / \mathrm{J}_{\mathrm{p}}$ can be written as

$$
\frac{\Delta P}{J_{p}}=\mu R_{m}+\frac{\alpha_{0} C_{0} \delta \mu}{P e}(\exp P e-1) \Delta P
$$

\subsection{The Multiple Solute Model}

During cross flow ultrafiltration the feed flows tangentially across the surface of the membrane from one end, retentate is collected at other end of membrane and permeate is collected across the membrane. Therefore cross flow ultrafiltration is also termed as tangential ultrafiltration. The principal advantage of this is that the gel layer formed on membrane surface is substantially washed away during the filtration process; it limits the buildup of the solids on the membrane surface due to turbulent flow at membrane surface. The membrane continuously rejects the solutes and these solutes are deposited on the membrane surface but due to cross currents and superficial velocity some of the solutes are removed from surface and enter into bulk solution due to back transport effect.
Thus in the cross flow ultrafiltration of multiple solute systems following assumptions are made:

1. The membrane rejects the solutes by sieving action and the solute-solute interactions are neglected.

2. Since the solute-solute interactions are neglected, the concentration of each solute can be determined by mass balance analysis with the consideration of back transport effect.

3. In the gel layer, each solute will have its independent value of diffusion, mass transfer coefficient and back transport coefficient.

Basis of above assumptions can be found in work done by Ahmad et al. The multiple solute model is based on mass balance analysis coupled with filtration theory (Darcy's law), resistance in series model and gel polarization model [15].

Thus for the MEUF of multiple solute system containing ' $n$ ' number of solutes ( $i=1,2,3, \ldots . n)$ the overall mass balance can be represented as in Figure 3.

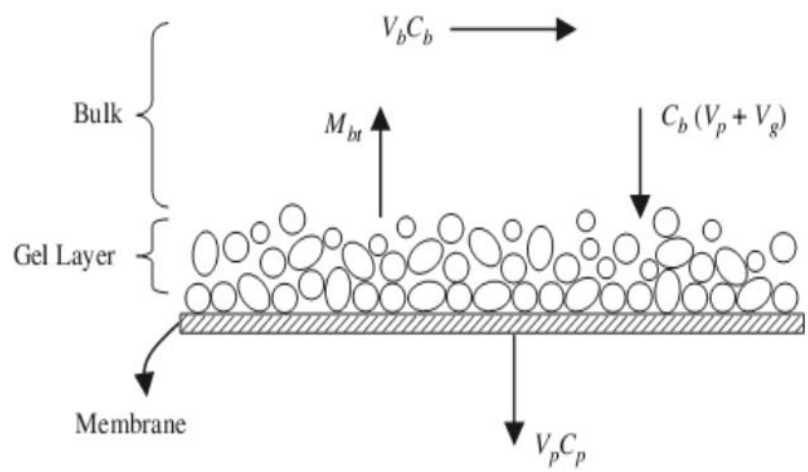

Figure 3: Overall mass balance over cross flow ultrafiltration of multiple solute system.

During the UF process, some of the solutes in the bulk are transported in to the permeate stream through the boundary layer and gel layer. However, for the simplicity of model, the mass balance analysis in the boundary layer is ignored by assuming that the total mass of solutes obtained in the boundary layer is negligible compared to the mass of solutes obtained in the gel layer. This assumption is applicable for the system operated under convection current created by cross-flow velocity or stirring action. After filtration time $\mathrm{t}$, the total solutes rejected by the membrane result in the solutes concentration rise in the gel layer and the remainder is being transported back into the bulk by convection current created by the superficial velocity. 
The mass of the total solutes in the gel layer at any filtration time $t$, is

$V_{g} C_{g}=\left(V_{p}+V_{g}\right) C_{b}-V_{p} C_{p}-M_{b t}$

Where,

$\mathrm{V}_{\mathrm{g}}=$ Total volume of gel layer up to time $\mathrm{t}, \mathrm{C}_{\mathrm{g}}=$ Total concentration of solutes in gel layer

$V_{p}=$ Total volume of permeate up to time $t, C_{p}=$ Total concentration of solutes in permeate

$\mathrm{C}_{\mathrm{b}}=$ Total concentration of solutes in bulk, $\mathrm{M}_{\mathrm{bt}}=$ Total back transport mass up to time $t$

Therefore the overall mass balance for $\mathrm{n}$ solutes can be given by equation

$V_{g} \sum_{i=1}^{n} C_{g i}=\left(V_{p}+V_{g}\right) \sum_{i=1}^{n} C_{b i}-V_{p} \sum_{i=1}^{n} C_{p i}-\sum_{i=1}^{n} M_{b t i}$

It has been assumed that the rate of back transport mass for each solute $i$ is proportional to the superficial velocity (v), and the concentration of the solute in the gel layer $\left(\mathrm{C}_{\mathrm{gi}}\right)$

$\frac{d M_{b t i}}{d t} \alpha v C_{g i}$

Back transport coefficient $\left(K_{b i}\right)$ for each solute i can be introduced in Eq. (14) [8]. Therefore Eq. (14) can be written as

$\frac{d M_{b t i}}{d t}=K_{b i} v C_{g i}$

Therefore integrating Eq. (15) at initial time $\mathrm{t}=0$ and back transport mass $M_{b t i}=0$ we get,

$M_{b t i}=K_{b i} v C_{g i}$

Substituting Eq. (16) into Eq. (13) and rearranging terms to give total volume of permeate $\left(V_{p}\right)$ up to time $t$, the equation becomes,

$V_{p} \sum_{i=1}^{n}\left(C_{b i}-C_{p i}\right)=V_{g} \sum_{i=1}^{n}\left(C_{g i}-C_{b i}\right)+v t \sum_{i=1}^{n} K_{b i} C_{g i}$

By rearranging above Eq. (17), we can get gel layer thickness $z$, with total gel layer volume $V_{g}=A_{m} z$, where $A_{m}$ is effective membrane area

$z=\frac{V_{p} \sum_{i=1}^{n}\left(C_{b i}-C_{p i}\right)}{A_{m} \sum_{i=1}^{n}\left(C_{g i}-C_{b i}\right)}-\frac{\sum_{i=1}^{n} K_{b i} C_{g i}}{A_{m} \sum_{i=1}^{n}\left(C_{g i}-C_{b i}\right)} v t$
The total volume flux of permeate $J_{p}$ can be calculated by using osmotic pressure model $[16,17]$

$J_{p}=\frac{1}{A_{m}} \frac{d V_{p}}{d t}=\frac{\Delta P-\Delta \pi}{\mu\left(R_{H}\right)}$

Where, $\Delta \mathrm{P}$ is transmembrane pressure (TMP), $\Delta \pi$ is osmotic pressure difference across the membrane, $\mu$ is viscosity of solution and $R_{H}$ is total hydraulic resistance of the system. The hydraulic resistance is equal to sum of the membrane resistance $R_{m}$ and resistance due to gel layer $R_{g}$, therefore above equation can be written as,

$J_{p}=\frac{1}{A_{m}} \frac{d V_{p}}{d t}=\frac{\Delta P-\Delta \pi}{\mu\left(R_{m}+R_{g}\right)}$

Total volume flux of permeate $J_{p}$ can also be determined by Darcy's law [8].

$J_{p}=\frac{1}{A_{m}} \frac{d V_{p}}{d t}=P_{m}\left(\frac{\Delta P_{c}}{\mu H}\right)$

Where $\Delta \mathrm{P}_{\mathrm{c}}$ is pressure drop across gel layer, $\mathrm{P}_{\mathrm{m}}$ is permeability coefficient and $H$ is effective gel layer thickness. Thus the resistance in series model can be obtained by combining Eq. (20) and Eq. (21) The volume permeate flux is given by

$J_{p}=\frac{\Delta P-\Delta \pi}{\mu\left(R_{m}+z / P_{m}\right)}$

Above equation can be written by substituting $z$ from Eq. (18) in Eq. (22), Thus final equation to determine volume flux of permeate in multiple solute model is given as below,

$\frac{1}{J_{p}}=a_{1}+a_{2} V_{p}-a_{3} t$

Where, the coefficients $a_{1}, a_{2}$ and $a_{3}$ are given by

$a_{1}=\frac{\mu R_{m}}{(\Delta P-\Delta \pi)}$

$a_{2}=\frac{\mu}{A_{m} \operatorname{Pm}(\Delta P-\Delta \pi)} \frac{\sum_{i=1}^{n}\left(C_{b i}-C_{p i}\right)}{\sum_{i=1}^{n}\left(C_{g i}-C_{b i}\right)}$

And

$a_{3}=\frac{\mu \nu}{A_{m} P m(\Delta P-\Delta \pi)} \frac{\sum_{i=1}^{n} K_{b i} C_{g i}}{\sum_{i=1}^{n}\left(C_{g i}-C_{b i}\right)}$ 
Eqs. (23)-(26) represents the volume flux of permeate in multiple solute system. This equations can be simultaneously solved to determine values of model parameters. After determining the model parameters, permeate flux and concentrations of solutes in permeate can be determined by solving Eqs. (23)-(26).

\section{RESULTS AND DISCUSSION}

\subsection{Input Parameters for Experiments}

Experiments have been carried out to determine various input parameters characterizing the modified resistance in series model and the multiple solute models. All experiments are carried out at dilute range of solutes.

\subsection{Determination of Model Parameters}

\subsubsection{Model Parameters for Modified Resistance in Series Model}

Modified resistance in series model is characterized by model parameters such as membrane resistance $\left(R_{m}\right)$, mass transfer coefficient $(k)$, boundary layer thickness $(\delta)$ and specific resistance coefficient $\left(\alpha_{0}\right)$. There are certain input parameters such as transmembrane pressure $(\Delta \mathrm{P})$, bulk concentration of solute $\left(C_{0}\right)$, effective membrane filtration area $\left(A_{m}\right)$ and viscosity $(\mu)$. Membrane resistance $\left(R_{m}\right)$ is determined by plotting graph of $\mathrm{DI}$ water flux $\left(\mathrm{J}_{\mathrm{w}}\right)$ verses TMP $(\Delta \mathrm{P})$, it is determined to be $1 \times 10^{12} \mathrm{~m}^{-1}$. The mass transfer coefficient $(k)$ is determined using gel polarization model. It is one of the most widely used model to correlate UF experimental data [18-20]. It can be represented by

$$
J_{p l i m}=k \ln \frac{C_{g}}{C_{0}}
$$

Where, $J_{\text {plim }}$ is limiting permeate flux, $\mathrm{C}_{\mathrm{g}}$ represents gel layer concentration, $\mathrm{C}_{0}$ bulk concentration of solute and $\mathrm{k}$ is mass transfer coefficient. Thus by plotting graph of $J_{\text {plim }}$ verses $\operatorname{lnC}_{0}$ we obtain slope of graph $-k$. The extrapolation to $J_{\text {plim }}=0$ will give the value of $\ln C_{g}$, and hence $\mathrm{C}_{\mathrm{g}}$.

Thus applying this model to experimental data as shown in Figure 4 we obtained value of mass transfer coefficient $(\mathrm{k})=6.00 \times 10^{-6} \mathrm{~m} \mathrm{~s}^{-1}$. The boundary layer thickness $(\delta)$ is determined from relation $k=D / \delta$, where $D$ is diffusion coefficient of solute, and is determined using Stokes Einstein equation. Value of boundary layer thickness, $\delta=5.73335 \times 10^{-6} \mathrm{~m}$.

Thus, by using experimental data of permeate flux at different TMP and at constant total bulk concentration $\mathrm{C}_{0}=2.810593 \mathrm{~kg} / \mathrm{m}^{3}$ (or $\mathrm{g} / \mathrm{lit}$ ) and constant inlet feed flow rate we can determine value of specific resistance coefficient $\left(\alpha_{0}\right)$. The value of $\alpha_{0}$ is determined using Eq. (11) from slope of graph $\Delta P / J_{p}$ verses $\mathrm{C}_{0}(\exp \mathrm{Pe}-1) \Delta \mathrm{P} / \mathrm{Pe}$ as shown in Figure 5 . Slope of graph $\alpha 0 \mu \delta=756.9$ therefore, the value of $\alpha_{0}$ obtained as $1.38965 \times 10^{11} \mathrm{~m} \mathrm{~mol}^{-1} \mathrm{~Pa}^{-1}$.

\subsubsection{Model Parameters for the Multiple Solute Model}

The multiple solute model is characterized by operating parameters transmembrane pressure $(\Delta \mathrm{P})$, superficial velocity $(\mathrm{V})$, total bulk concentration $\left(\mathrm{C}_{\mathrm{b}}\right)$, bulk concentration of each solute $\left(\mathrm{C}_{\mathrm{bi}}\right)$ and membrane

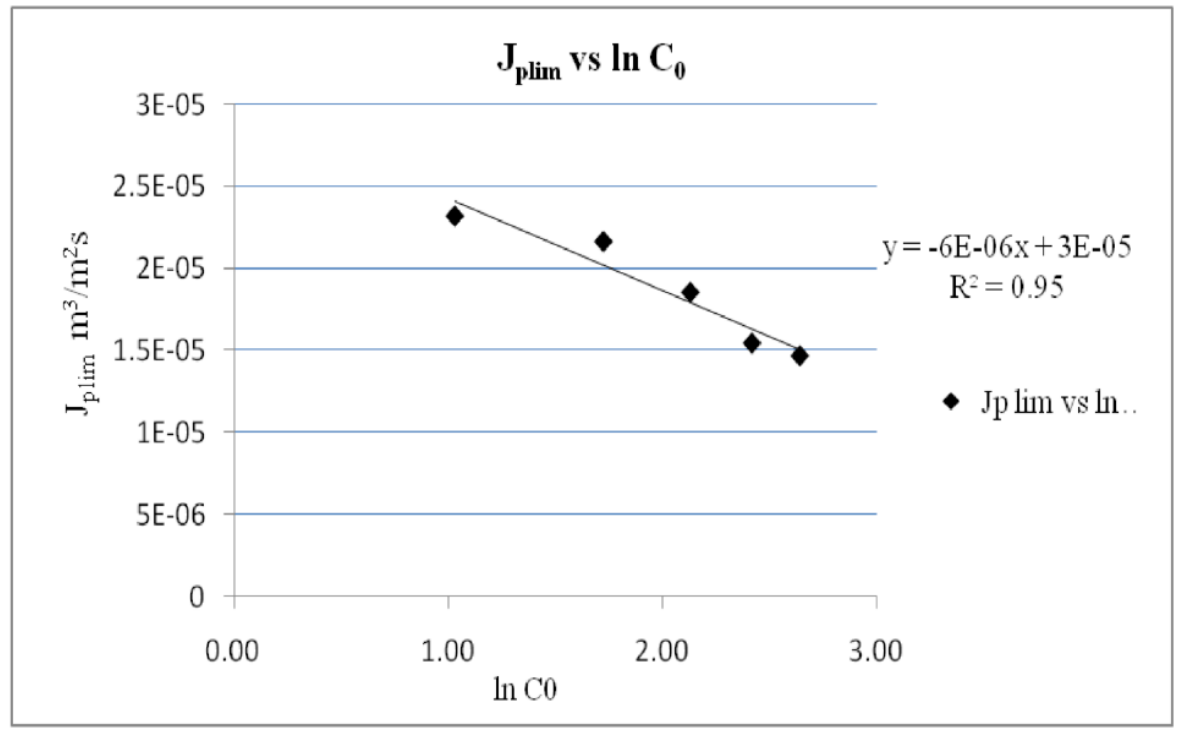

Figure 4: Variation of limiting permeate flux $J_{\text {plim }} v s$. In $C_{0}$ at inlet feed flow rate $V=100 \mathrm{~m} / / \mathrm{min}$. 


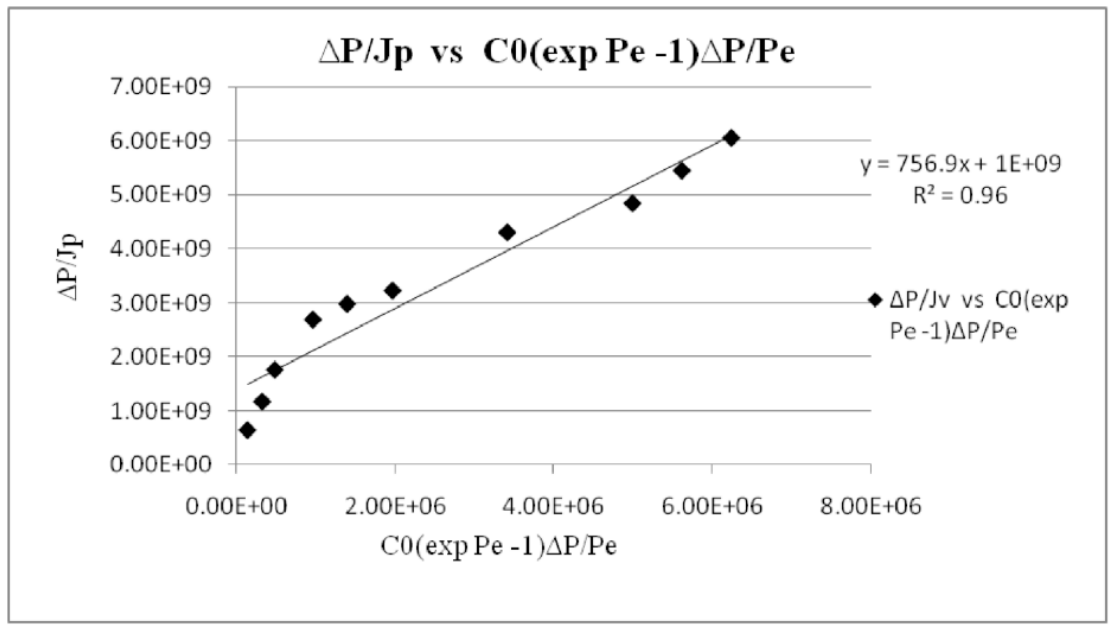

Figure 5: Plot of $\Delta \mathrm{P} / \mathrm{J}_{\mathrm{p}}$ vs $\mathrm{C}_{0}(\exp \mathrm{Pe}-1) \Delta \mathrm{P} / \mathrm{Pe}$ at inlet feed flow rate $\mathrm{V}=100 \mathrm{ml} / \mathrm{min}$.

parameters such as membrane resistance $\left(R_{m}\right)$, osmotic pressure difference $(\Delta \pi)$, permeability coefficient $\left(P_{m}\right)$, viscosity $(\mu)$, back transport coefficient $\left(\mathrm{K}_{\mathrm{bi}}\right)$ and mass transfer coefficient $\left(\mathrm{k}_{\mathrm{i}}\right)$ of each solute.

The membrane resistance $\left(R_{m}\right)$ can be determined from slope of $\mathrm{DI}$ water flux $\left(\mathrm{J}_{\mathrm{w}}\right)$ verses $\Delta \mathrm{P} / \mu$ graph as shown in Figure 6. Viscosity $(\mu)$ of feed solution is determined using Ostwald's viscometer and is determined to be 0.00095 Pa.s.

Thus, determined value of membrane resistance $\left(R_{m}\right)$ from slope is $1 \times 10^{12} \mathrm{~m}^{-1}$. The mass transfer coefficient $\left(\mathrm{k}_{\mathrm{i}}\right)$ for each solute is can be determined using velocity variation method [21]. This is done by linearization of gel polarization model [15], which yields

$$
\ln \left(\frac{1}{R_{o i}}-1\right)=\frac{1}{q}\left(\frac{J_{p, s s}}{v^{n}}\right)+\ln \left(\frac{1}{R_{i}}-1\right)
$$

Where, Roi is the observed rejection of solute $i$ and $\mathrm{Ri}$ is the true rejection of solute $i$, these can be given by following equations

$R_{o i}=1-\frac{C_{p i}}{C_{b i}}$

and

$R_{i}=1-\frac{C_{p i}}{C_{g i}}$

Where, $\mathrm{C}_{\mathrm{bi}}$ is concentration of solute in bulk i.e. feed, $\mathrm{C}_{\mathrm{pi}}$ is solute concentration in permeate stream, $\mathrm{C}_{\mathrm{gi}}$ is concentration of solute in gel layer, $\mathrm{v}$ is superficial velocity of feed, and $q$ and $\eta$ are constants. The coefficients $q$ and $\eta$ are obtained from the best linear fit in the plot of $\ln \left(1 / R_{o i}-1\right)$ versus $J_{p, s s} / v^{\eta}$. The

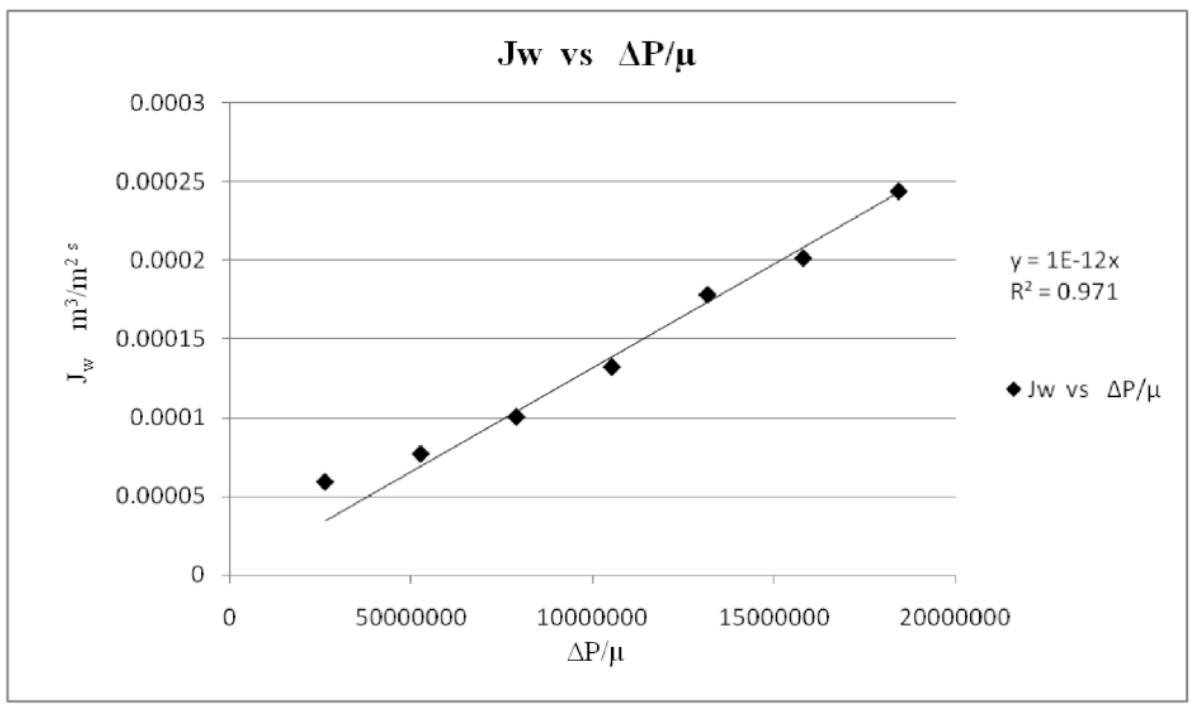

Figure 6: Plot of $\mathrm{DI}$ water flux $\left(\mathrm{J}_{\mathrm{w}}\right)$ vs $\Delta \mathrm{P} / \mu$ to determine membrane resistance, at $\mathrm{V}=100 \mathrm{ml} / \mathrm{min}$. 
Table 1: Input Parameters for Separation of Ni (II) Using MEUF

\begin{tabular}{|c|c|c|c|c|c|c|}
\hline Sr. no. & Parameter & Notation & Value & Unit & SI Value & Unit \\
\hline 1 & Transmembrane pressure TMP & $\Delta \mathrm{P}$ & 0.5 & Bar & 50000 & $\mathrm{~N} / \mathrm{m}^{2}$ \\
\hline 2 & Surfactant to metal ratio & $\mathrm{S} / \mathrm{M}$ & 6 & & & \\
\hline 3 & Nonionic to lonic surfactant ratio & N.S/I.S & 0.2 & & & \\
\hline 4 & Membrane area & $A_{m}$ & 21.53 & $\mathrm{~cm}^{2}$ & 0.002153 & $\mathrm{~m}^{2}$ \\
\hline 5 & Inlet feed flowrate & V & 100 & $\mathrm{ml} / \mathrm{min}$ & 1.66667E-06 & $\mathrm{m}^{3} / \mathrm{m}^{2} \cdot \mathrm{s}$ \\
\hline 6 & Viscocity & $\mu$ & 0.00095 & Pa.s & 0.00095 & Pa.s \\
\hline 7 & Molecular wt. of $\mathrm{Ni}$ & MW Ni & 58.6934 & $\mathrm{~g} / \mathrm{mol}$ & 0.0586934 & $\mathrm{Kg} / \mathrm{mol}$ \\
\hline 8 & Molecular wt. SDS & MW SDS & 288.38 & $\mathrm{~g} / \mathrm{mol}$ & 0.28838 & $\mathrm{~g} / \mathrm{mol}$ \\
\hline 9 & Molecular wt. of TW80 & MW TW80 & 1310 & $\mathrm{~g} / \mathrm{mol}$ & 1.31 & $\mathrm{~kg} / \mathrm{mol}$ \\
\hline 10 & Initial conc. of Nickel & $\mathrm{C}_{01}$ & 1 & $\mathrm{mM}$ & 0.0586934 & $\mathrm{~kg} / \mathrm{m}^{3}$ \\
\hline 11 & Initial conc. of SDS & $\mathrm{C}_{02}$ & 5 & $\mathrm{mM}$ & 1.4419 & $\mathrm{~kg} / \mathrm{m}^{3}$ \\
\hline 12 & Initial conc. of TW80 & $\mathrm{C}_{03}$ & 1 & $\mathrm{mM}$ & 1.31 & $\mathrm{~kg} / \mathrm{m}^{3}$ \\
\hline 13 & Total initial conc. & $\mathrm{C}_{0}$ & 7 & $\mathrm{mM}$ & 2.8105934 & $\mathrm{~kg} / \mathrm{m}^{3}$ \\
\hline
\end{tabular}

mass transfer coefficient is represented as a function of superficial velocity $\mathrm{v}$,

$k_{i}=q v^{\eta}$

The concentration of solute in gel layer can be determined using total mass balance. The back transport coefficient $\left(\mathrm{K}_{\mathrm{bi}}\right)$ of each solute is determined from slope of graph of $C_{p i}$ verse $v C_{g i} / A_{m} J_{p, s s}$. For determination of unknown parameters $a_{1}, a_{2}$ and $a_{3}$ in Eq. (23), several experimental data with permeate volume $\mathrm{Vp}$ and time $\mathrm{t}$ as independent variables and $1 / \mathrm{Jp}$ as dependent variables are collected. These data is fitted in Eq. (23) The parameters $a_{1}, a_{2}$ and $a_{3}$ are determined using the Levenberg- Marquardt method using MATLAB. Using this values of $a_{1}, a_{2}$ and $a_{3}$ unknown parameters $\Delta \pi$ and $P_{m}$ have been determined by solving Eq. (24)-(26). These parameters are the characteristics of multiple solute UF systems under a constant temperature, pressure and same solutes and membrane combination [15]

\subsection{Validating Models by Comparing with Experimental Data}

Mathematical models have been validated by comparing with experimental data. The modified resistance in series model can only be used to determine permeate flux by using operating parameters like $\Delta \mathrm{P}, \mathrm{C}_{0}, \mu$ and model parameters such as $\alpha_{0}, \delta, \mathrm{k}$. The simulation have been carried out using Microsoft Excel.
Determination of model parameters for the multiple solute models is more tedious job, and the calculations are done using Microsoft Excel. The simulation to determine coefficients $a_{1}, a_{2}$ and $a_{3}$ in Eq. (23) using Levenberg-Marquardt method are done using MATLAB. This model can be used to predict steady state permeate flux $J_{p, s s}$ and concentrations of each solute in the permeate $\mathrm{C}_{\mathrm{pi}}$. Prediction of Jp,ss and $\mathrm{Cpi}$ is done by simulation in MATLAB.

Comparison of experimental data and simulation results at constant trasnmembrane pressures are given in Table 3 below.

From experimental data it is observed that \% rejection for $\mathrm{Ni}(\mathrm{II})$ using MEUF is $95 \%-99 \%$, therefore from Table $\mathbf{4}$ we can say that multiple solute model can be accurately predict concentrations of solute in permeate stream.

Figure 7 shows a plot of steady state permeate flux $\left(\mathrm{J}_{\mathrm{pss}}\right)$ verses TMP $(\Delta \mathrm{P})$. From Figure $\mathbf{8}$ we can compare steady state permeate flux value obtained by using model with the experimental value. It is observed that simulation results for steady state permeate flux obtained by multiple solute model are in good in agreement with the experimental results as compared to simulation values obtained by using modified resistance in series model.

In the multiple solute model the volume flux of permeate $\left(J_{p}\right)$ is can be estimated by solving Eqs. (23)(26) simultaneously. 
Table 2: Estimated Parameters for Multiple Solute Model

\begin{tabular}{|c|c|c|c|}
\hline Sr. no. & Parameter & Notation & Value \\
\hline \hline 1 & Transmembrane Pressure & $\Delta \mathrm{P}$ & $\mathrm{N} / \mathrm{m}^{2}$ \\
\hline 2 & Membrane Area & $\mathrm{Am}$ & 0.002153 \\
\hline 3 & Superficial velocity & $\mathrm{v}$ & 0.000774114 \\
\hline 4 & Membrane resistance & $\mathrm{Rm} / \mathrm{s}$ & $1 \mathrm{E}+12$ \\
\hline 5 & Osmotic presure difference & $\Delta \pi$ & 14680.49172 \\
\hline 6 & Permeability coefficient & $\mathrm{Nm} / \mathrm{m}^{2}$ & $\mathrm{~m}^{2}$ \\
\hline 7 & Viscosity & $\mu$ & $7.71903 \mathrm{E}-07$ \\
\hline
\end{tabular}

\begin{tabular}{|c|c|c|c|c|c|c|}
\hline Sr. no. & Parameter & Notation & Unit & $\mathbf{N i}$ & SDS & TW80 \\
\hline 8 & Mass Transfer Coeff. & Ki & $\mathrm{m} / \mathrm{s}$ & 7.03475E-06 & $1.18 \mathrm{E}-05$ & $5.75 \mathrm{E}-06$ \\
\hline 9 & Back Mass transfer co. & Kbi & $\mathrm{m}^{2}$ & 0.000003 & 0.000009 & 0.000001 \\
\hline 10 & Inlet/Bulk concentration & Cbi & $g / l i t$ & 0.0586934 & 1.4419 & 1.31 \\
\hline 11 & Total/Bulk concentration & $\mathrm{Cb}$ & g/lit & 2.8105934 & & \\
\hline
\end{tabular}

Table 3: $\quad J_{p, s s}$ by Experimental Data and Simulation Results at Different $\Delta P$ Values

\begin{tabular}{|c|c|c|c|c|}
\hline \multirow{2}{*}{ Sr. no. } & DP N/m & \multicolumn{3}{|c|}{ Jpss $\left(\mathrm{m}^{3} / \mathbf{m}^{2} . \mathbf{s}\right)$} \\
\cline { 3 - 5 } & & Experimental & $\begin{array}{c}\text { Modified resistance in series } \\
\text { model }\end{array}$ & Multiple solute model \\
\hline \hline 1 & 25000 & $2.79 \mathrm{E}-05$ & $1.89 \mathrm{E}-05$ & $2.90 \mathrm{E}-05$ \\
\hline 2 & 50000 & $3.40 \mathrm{E}-05$ & $2.29 \mathrm{E}-05$ & $3.43 \mathrm{E}-05$ \\
\hline 3 & 75000 & $3.60 \mathrm{E}-05$ & $2.41 \mathrm{E}-05$ & $3.67 \mathrm{E}-05$ \\
\hline 4 & 100000 & $4.03 \mathrm{E}-05$ & $2.47 \mathrm{E}-05$ & $4.06 \mathrm{E}-05$ \\
\hline
\end{tabular}

Table 4: Values of Cpi of each Solute and \% Rejection by Simulation Using Multiple Solute Model

\begin{tabular}{|c|c|c|c|c|c|c|c|}
\hline Sr. no. & $\Delta P N / m^{2}$ & $C_{P 1}(N i) g / l i t$ & $\% \mathbf{R}_{1}$ & $\mathrm{C}_{\mathrm{P} 2}(\mathrm{SDS}) \mathrm{g} / \mathrm{lit}$ & $\% \mathbf{R}_{2}$ & $\mathrm{C}_{\mathrm{P}_{3}}(\mathrm{TW} 80) \mathrm{g} / \mathrm{lit}$ & $\% \mathbf{R}_{3}$ \\
\hline 1 & 25000 & 0.0014 & 97.61472 & 0.2971 & 79.39524 & 0.3955 & 69.80916 \\
\hline 2 & 50000 & 0.003 & 94.88869 & 0.3884 & 73.06332 & 0.39 & 70.22901 \\
\hline 3 & 75000 & 0.0028 & 95.22945 & 0.3725 & 74.16603 & 0.2889 & 77.94656 \\
\hline 4 & 100000 & 0.0027 & 95.39982 & 0.4238 & 70.60823 & 0.2844 & 78.29008 \\
\hline
\end{tabular}

As we know that permeate flux can be given as $J p=d V_{p} / A_{m} d t$, where $\mathrm{V}_{\mathrm{p}}$ is permeate volume at time $\mathrm{t}$ and it can be obtained by integrating Eq. (23) in the form of first order ordinary differential equation as below

$$
\frac{d v_{p}}{d t}=\frac{A_{m}}{a_{1}+a_{2} V_{p}-a_{3} t}
$$

The $V_{p}$ can be obtained by numerical integration of Eq. (32) using higher order Runge-Kutta method at equal time intervals [22].

The Figures $\mathbf{9}$ and $\mathbf{1 0}$ shows plot of permeate flux $(\mathrm{Jp})$ verses time $(\mathrm{t})$ at different TMP, from this figures we can compare nature of plots by using experimental data and by using simulation results of modified 


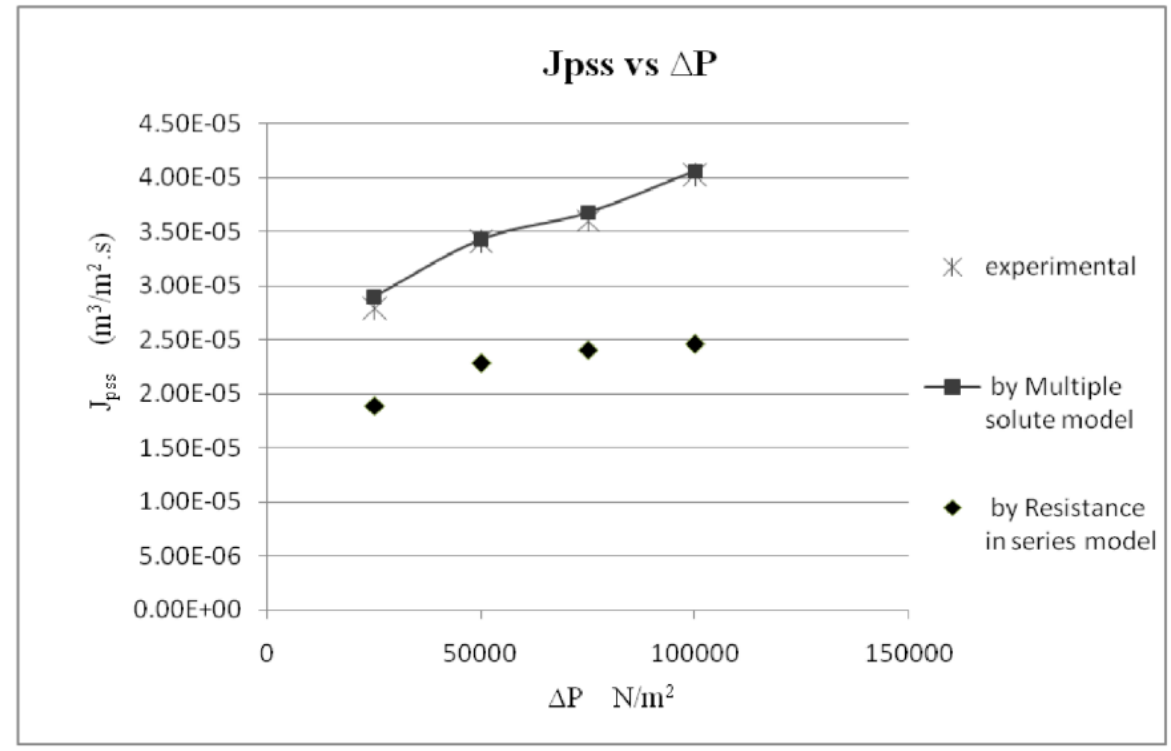

Figure 7: Plot of Jpss vs $\Delta \mathrm{P}$ from experimental data and simulation results.

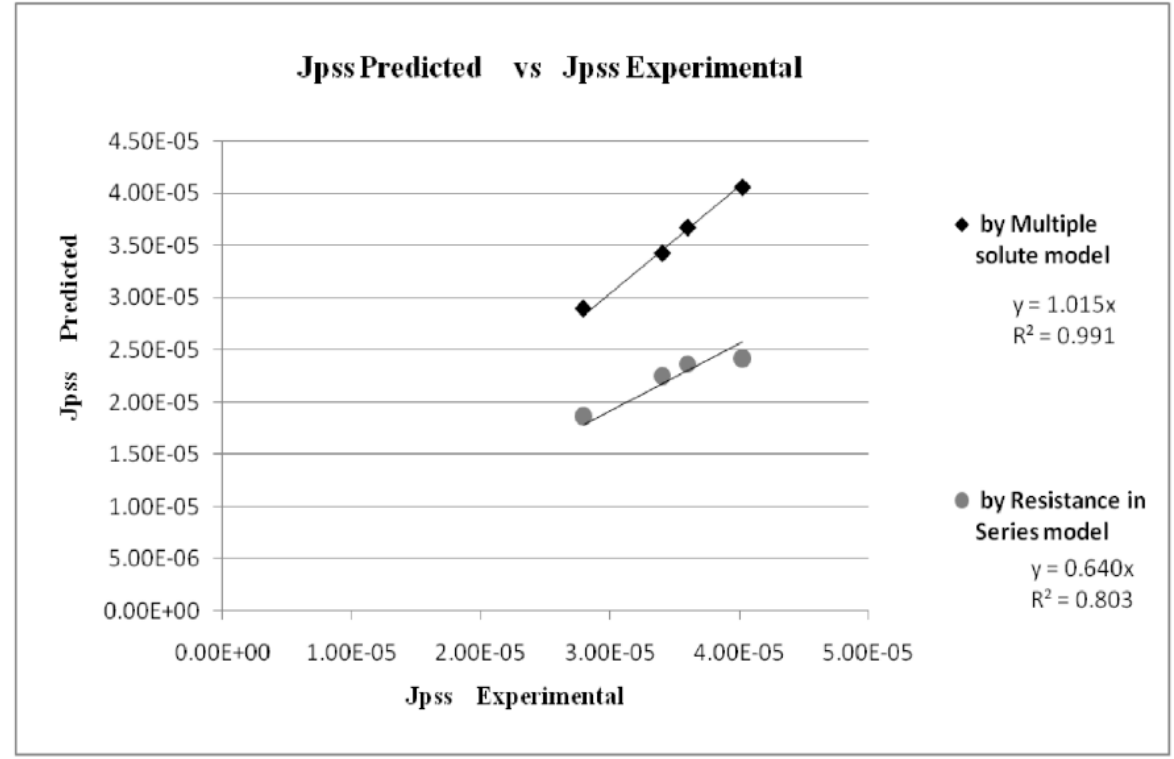

Figure 8: Plot of Jpss predicted vs Jpss experimental using multiple solute model and modified resistance in series model.

resistance in series model and multiple solute model respectively.

\section{CONCLUSIONS}

The selection of suitable model is very important for optimization, process design and scale-up of a system. The UF system in present study for separation of $\mathrm{Ni}(\mathrm{II})$ from wastewater using SDS and Tween 80 is a multiple solute system. From Figures $\mathbf{7}$ and $\mathbf{8}$ it is observed that experimental results are not in agreement with modified resistance in series model and this model can be used to predict only permeate flux value, it cannot predict the solute concentration in permeate. The modified resistance in series model accounts for the influence of solute concentration in the boundary layer on the gel polarization resistance. The mass transfer coefficient $k$ determined using this model is based on the total initial concentration of solutes $\left(\mathrm{C}_{0}\right)$ and the specific resistance coefficient $\alpha_{0}$ changes with feed velocity.

It is observed that the simulation results obtained using multiple solute model are in good agreement with the experimental results for system in present study, containing three solutes. The validity of multiple solute model is checked by comparing with simulation results using modified resistance in series model. The model successfully predicted the volume flux of permeate at different transmembrane pressures. Also the permeate concentrations of all the three solutes are determined 


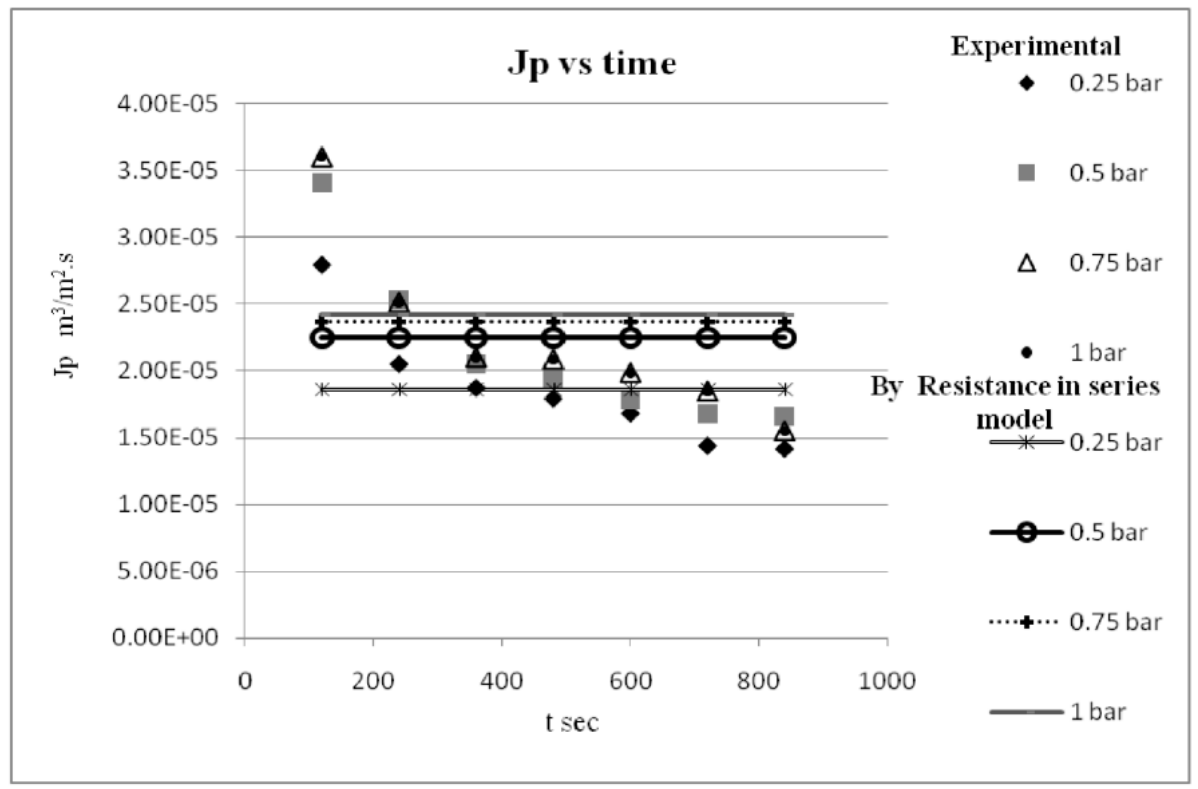

Figure 9: Plot of $J_{p}$ vs time by modified resistance in series model at $V=100 \mathrm{ml} / \mathrm{min}$.

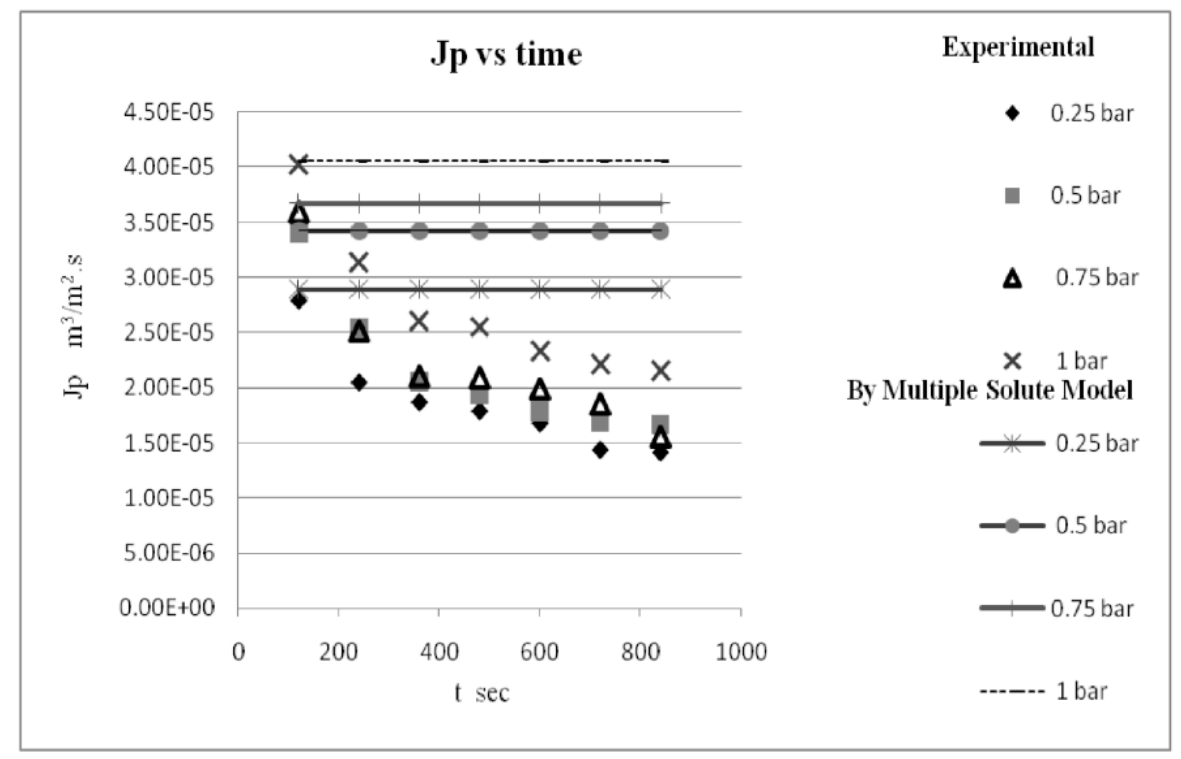

Figure 10: Plot of $J_{p} v s$ time by multiple solute model at $V=100 \mathrm{ml} / \mathrm{min}$.

and the $\%$ rejection of all the solutes are also determined; it is observed that this values are in good agreement with the experimental data. The proposed multiple solute model based on mass balance analysis coupled with the filtration theory, resistance in series model and gel polarization model can be successfully used for predicting behavior of MEUF systems.

\section{REFERENCES}

[1] Baker RW. Membrane Technology and Applications, second ed., McGraw-Hill, New York 2000.

[2] Mulder M. Basic Principles of Membrane Technology, Kluwer Academic Publishers, Dordrecht 1996.
[3] Manchalwar SM, Anthati VA, Marathe KV. Simulation of micellar enhanced ultrafiltration by multiple solute model. Jof Hazardous Mater 2010; 184: 485-92. http://dx.doi.org/10.1016/j.jhazmat.2010.08.060

[4] Monfared MA, Kasiri N, Salahi A, Mohammadi T. Modeling ultrafiltration of gelatin-water suspension by computational fluid dynamics. Chem Eng Res Design (CHERD) 2011; 90: 1098-104. http://dx.doi.org/10.1016/j.cherd.2011.11.010

[5] Tansel B, Bao WY, Tansel IN. Characterization of fouling kinetics in ultrafiltration systems by resistance in series model. Desalination 2000; 129: 7-14. http://dx.doi.org/10.1016/S0011-9164(00)00046-1

[6] Kumar NSK, Yes MK, Cheryan M. Ultrafiltration of soy protein concentrate: performance and modeling of spiral and tubular polymeric modules. J Membr Sci 2004; 244: 235-42. http://dx.doi.org/10.1016/j.memsci.2004.06.056 
[7] Gehlert G, Adbulkadir M, Fuhrmann J, Hapke J. Dynamic modeling of an ultra filtration module for use in a membrane bioreactor. J Membr Sci 2005; 248: 63. http://dx.doi.org/10.1016/j.memsci.2004.09.026

[8] Bhattacharjee C, Datta S. Analysis of polarized layer resistance during ultrafiltration of PEG-6000: an approach based on filtration theory. Sep Purif Technol 2003; 33: 11526.

http://dx.doi.org/10.1016/S1383-5866(02)00142-9

[9] Yeh HM, Cheng TW. Resistance-in-Series for Membrane Ultrafiltration in Hollow Fibers of Tube-and-Shell Arrangement. Sep Sci Technol 1993; 28: 1341-55. http://dx.doi.org/10.1080/01496399308018041

[10] Paris J, Guichardon P, Charbit F. Transport phenomena in ultrafiltration: a new two dimensional model compared with classical models. J Membr Sci 2002; 207: 43-58. http://dx.doi.org/10.1016/S0376-7388(01)00752-9

[11] Chhatre AJ, Marathe KV. Modeling and performance study of MEUF of divalent metal ions in aqueous streams. Sep Sci Technol 2008; 43(11): 3286-304. http://dx.doi.org/10.1080/01496390802212641

[12] Das C, DasGupta S, De S. Prediction of permeate flux and counterion binding during crossflow micellar enhanced ultrafiltration. Colloids Surf A 2008; 318: 125-33. http://dx.doi.org/10.1016/j.colsurfa.2007.12.027

[13] Jadhav SR, Verma N, Sharma A, Bhattachayra PK. Flux and retention analysis during micellar enhanced ultra filtration for the removal of phenol and aniline. Sep Purif Technol 2001; 24: $541-57$ http://dx.doi.org/10.1016/S1383-5866(01)00154-X

[14] Damak K, Ayadi A, Zeghmati B, Schmitz P. A new NavierStokes and Darcy's law combined model for fluid flow in crossflow filtration tubular membranes. Desalination 2004; 161: $67-77$

http://dx.doi.org/10.1016/S0011-9164(04)90041-0
[15] Ahmed AL, Chong MF, Bhatia S. Ultrafiltation modeling of multiple solutes systems for continuous crossflow process. Chem Eng Sci 2006; 61: 5057-69. http://dx.doi.org/10.1016/..ces.2006.03.017

[16] Yeh HM, Cheng TW. Osmotic-pressure model with permeability analysis for ultrafiltration in hollow-fiber membrane modules. Sep Technol 1993; 3: 91. http://dx.doi.org/10.1016/0956-9618(93)80008-F

[17] Karode SK. Unsteady state flux response: a method to determine the nature of the solute and gel layer in membrane filtration. J Membr Sci 2001; 188: 9-20. http://dx.doi.org/10.1016/S0376-7388(00)00644-X

[18] Blatt WF, Dravid A, Michael AS, Nelsen L. Solute polarization and cake formation in membrane ultrafiltration: causes, consequences, and control techniques, in: Flinn JE, Ed. Membrane Science and Technology, Plenum Press, New York 1970; pp. 47-97. http://dx.doi.org/10.1007/978-1-4684-1851-4 4

[19] Nakao S, Yumoto S, Kimura S. Analysis of rejection characteristics of macromolecular gel layer for low molecular weight solutes in ultrafiltration. J Chem Eng Jpn 1982; 15(6): 463-68. http://dx.doi.org/10.1252/jcej.15.463

[20] Yeh HM. Modified gel-polarization model for ultrafiltration in hollow-fiber membrane modules. Sep Sci Technol 1996; 31(2): 201-11. http://dx.doi.org/10.1080/01496399608000690

[21] Ahmad AL, Chong MF, Bhatia S. Mathematical modeling and simulation of the multiple solutes system for nanofiltration process. J Membr Sci 2005; 253: 103-15. http://dx.doi.org/10.1016/j.memsci.2005.01.005

[22] Chapra SC, Canale RP. Numerical Methods for Engineers, McGraw Hill, New York 1998. 